\title{
Transient global amnesia: an extensive case report
}

\author{
BARRY GORDON AND OSCAR S. M. MARIN \\ From the Departments of Neurology, Baltimore City Hospitals, and The Johns Hopkins Hospital, \\ Baltimore, Maryland, USA
}

\begin{abstract}
SUMMARY A case of transient global amnesia was studied in detail. Of note was a temporally extensive, although quite patchy, retrograde amnesia during the event for information recallable at other times. While a consolidation block can explain the anterograde amnesia in transient global amnesia, the profound retrograde amnesia requires an additional block in the retrieval of old, established memories.
\end{abstract}

\begin{abstract}
Although cases of transient global amnesia have been reported frequently since its initial description by Bender (1956), the neuropsychological examination of these patients has usually been quite limited. There have only been three reports, to our knowledge, in which patients were investigated in some detail during the episode (Fisher and Adams, 1964; Patten, 1971; Shuttleworth and Wise, 1973). We report a fourth case, with relatively extensive investigation of the memory defect during the episode. Taken together with other evidence, the nature of the retrograde deficit in transient global amnesia may have particular importance for theories of verbal memory.
\end{abstract}

\section{Case report}

This 55 year old, right handed, college-educated woman was admitted to hospital in May 1976 for evaluation of two episodes of memory loss. She was in otherwise excellent health.

The first episode had occurred in May 1973. She awoke without incident and drove nearly 40 miles to a routine appointment with a gynaecologist at 9.30 a.m. The gynaecologist remembered her as acting normally, showing him pictures of her family, and carrying on a normal conversation. She then went to visit an aunt.

While there, she was asked about her recent grandchild and did not remember the child's name. She then began to get very thirsty. At about $2.30 \mathrm{pm}$ she suddenly looked up and said that she could not remember any of the events of the day,

Address for reprint requests: Dr B. Gordon, Department of Neurology, Baltimore City Hospitals, 4940 Eastern Avenue, Baltimore, Maryland 21224, USA.

Accepted 16 December 1978 and asked what she was doing there. She had to be told about the events earlier that day, and even called up her gynaecologist to confirm them. Initially, she could not remember events of the previous weekend either, but gradually was able to remember everything between the time she began to drive in the morning to just before looking up in bewilderment. She remembered subsequent events quite well. A later medical evaluation was normal.

She was well until March 1976. She planned and started a bridge club meeting at her home at $10.00 \mathrm{am}$, serving her company well, carrying on conversation, and playing a good hand of bridge. In the afternoon she was telephoned about a grandson's injury. She drove (with a friend) 40 miles to her daughter's residence to be of assistance, but had some difficulty remembering the route and got lost twice. When she arrived, she summoned her husband, and they started back home with one of her grandchildren. While they were driving, at about $4.40 \mathrm{pm}$, she suddenly asked why she was on the highway and why her grandson was with them. She seemed somewhat confused, according to her husband, and was again very thirsty for several hours. Afterwards, she had no memory of the day's events until after the time she became thirsty in the car.

On evaluation in May 1977, her mental status was normal, without evidence of dysphasia. She remembered six digits forwards and backwards and three objects after five minutes; she had excellent recall of previous events, and readily subtracted serial sevens. General physical and neurological examination was completely normal. Routine blood chemistry, haematology, and sedimentation rate values were normal. Skull radiography, EMI 
scan, and spinal fluid (including IgG and routine smears) were normal. An EEG done with nasopharyngeal leads after sleep deprivation was "slightly abnormal" for age with bitemporal sharp and slow activity and occasional spikes especially on the left.

The day after her EEG, she was presented at rounds and described her episodes to the staff. She then (successfully) took a complicated walk back to her room in another part of the hospital. Upon arriving, she summoned the nurses, stating she had trouble remembering how she had returned. She was examined by the resident doctor almost immediately, and found to be somewhat worried and tearful. Gradually, she calmed down. Physical and general neurological examinations were completely normal.

NEUROPSYCHOLOGICAL TESTING DURING EPISODE In spontaneous conversation, her language was appropriate without hesitations or defects in pronuciation, intonation, or syntax. Her vocabulary was normal, without difficulty in finding words or expressions, and without paraphasias. Sentences were at times compounded and long.

Her digit span was 5-6, that of words $7-8$. She also had normal immediate recall of letters, sentences, compound rhythms, and objects that had been pointed to. Tactile recognition was normal. Movements were well repeated with the left hand, but, surprisingly, were only vaguely repeated, if at all, with the right. Her spontaneous gestures and manners were totally normal.

\section{Anterograde defects}

The patient was unable to repeat a series of three numbers, letters, or words; repeat a sentence; point to three objects; or repeat a rhythm or movement after about 20 or 30 seconds, if rehearsal was prevented. Clustering of word series into semantic associates did not facilitate recall. Isolating events or describing peculiar characteristics did not help, as in the following example.

Examiner-“"Imagine that you have in your arms a locomotive, a very heavy locomotive. Can you imagine it? Now, imagine that you are wrapping this enormous and heavy locomotive in newspaper. Can you imagine that?"

Fifteen seconds later the patient was totally unable to remember. Cueing was not helpful in any of these tasks. She had no recall even when asked "What happened to this very heavy thing that I asked you to hold in your arms. Do you remember something about a locomotive? What happened to it? What did I ask you to do with it?" Cueing in serial recall, by sentences, was of no help. A short story was recalled after some cueing in a general way with great uncertainty and a number of confabulatory elements.

Over the course of the examination, the patient did not seem to assimilate any of the new events or exercises, their temporal series, nor the names of the examiners. The patient would ask, in a very polite but stereotyped manner as if it were a new event, "Excuse me, I know that this is a silly question, but what am I doing here?" The examiner made exactly the same reply each time. "You are in this place because of some trouble with memory which you seem to have. You will be well very soon." This same conversation took place 15 to 20 times, with the same degree of surprise on the part of the patient. No recollection of it was ever noticed. The patient was repeatedly urged to try to learn the name of the examiner. Rehearsing the name aloud did not help. Association by phonology or by meaning failed as well. Only by the end of the interview was the patient able to remember (incorrectly) a similar sounding name. From that time on she was able to retrieve the incorrect name, but always with effort. And despite correction, it was always incorrect.

\section{Retrograde amnesia}

She did not know the date or the year, where she was or how many days she had been there. When her resident physician returned, she failed to recognise him, although she stated that she felt reassured by his presence. (In a second entrance he was spontaneously called by his name). Family events were vaguely remembered, but during the examination her husband phoned and she recognised his voice.

She did not remember anything of importance about the terms "bicentennial year" or "election year." Although she lived in Washington DC, she did not remember the President or his officials. She did not remember the previous President or Watergate. She was unable to remember the President whose name began with "K" (Kennedy). Once reminded of his name, which she recognised immediately, she was not able to remember what happened to him. Although she recalled a "catastrophe," she could not remember a detail. Given a choice of four cities as the site, she hesitatingly picked Washington. She could not recall the assassin and the name Oswald was unfamiliar to her. She could not remember who Roosevelt was, although she could explain what Pearl Harbor meant. 
Other testing

Simple mental calculations, imagery, abstractions, and interpretation of proverbs were all normal. She was able to enumerate objects within a category normally (furniture, people in uniforms, fruits, means of transportation). Given a set of characteristics of an object, she was able to name the object-that is, television set, microscope. She was able to give a fairly good explanation of how an aeroplane flies. She explained in detail the rules of contract bridge playing and some strategies.

An EEG was performed immediately after the testing, which was minimally abnormal because of frequent minor anterior and midtemporal and nasopharyngeal sharp waves, bilateral but more marked on the left. No spikes were seen, and there were no other abnormalities.

She seemed to be improving while the EEG was being recorded and shortly thereafter appeared to have recovered completely. She was nervous, and somewhat thirsty. She recognised the resident physician and knew his name, but had no memory of being at rounds. She was unclear about many events (see below), and was worried that her problem could be psychological.

The next day the patient recognised the examiner and remembered seeing him some time before ("perhaps a day"). She knew his name, but this had been mentioned inadvertently to her that morning. There was only a very vague recollection of what had been done during the previous day's examination. She could not remember any of the details of the various tasks. She misplaced her position and the examiner's, and misplaced other physicians and their roles. However, she was able perfectly to recall premorbid information that she had been unable to remember during the episode.

On review 15 months later, she had had no further episodes. Her mental status and neurological examinations remained normal.

\section{Discussion}

The functional deficit in our patient appears identical to that described by Fisher and Adams (1964), Patten (1971) and Shuttleworth and Wise (1973) in their patients with transient global amnesia. But more importantly, transient global amnesia is similar in many respects to the permanent amnesias due to alcoholic Korsakoff's disease (Victor et al., 1971) or focal anatomical damage (Milner et al., 1968). Like these disorders, the transient global amnestic seems to have an intact short-term memory (measured by digit and word spans) and dense anterograde amnesia if rehearsal is prevented.
Perhaps the most important feature of our 을 patient and of the others with transient global $\underset{\otimes}{z}$ amnesia was the striking retrograde amnesia, since different explanations of the amnestic process predict characteristically different retrograde amnesias. The classical consolidation hypothesis (Shuttleworth and Morris, 1966) which postulates a block in the conversion of short-term memories to long-term permanent ones, predicts a relatively brief retrograde amnesia. The retrieval explanation (Warrington and Weiskrantz, 1970) assumes that $\vec{\Rightarrow}$ memories are stored correctly, but that their retrieval is somehow impaired. All memories, both recent and remote, would be affected by this retrieval difficulty, so the retrograde amnesia would perhaps extend over the lifetime of the individual.

Experimental studies of retrograde amnesia in permanent amnestics have given conflicting results. Marslen-Wilson and Teuber (1975) and Squire and Slater (1978) found temporally limited retrograde amnesias in two amnestic patients. Sanders and Warrington $(1971,1975)$, studying a group of mostly alcoholic amnestics, found a uniformly ex $-\frac{\vec{N}}{\sim}$ tensive retrograde amnesia extending back oves decades. Seltzer and Benson (1974), employing $\vec{\Phi}$ modification of the test used by Sanders anf Warrington, discovered an extensive but diminishe ing retrograde amnesia extending back over years ${ }_{C}$ in a group of patients with Korsakoff's syndromeg

Part of this disagreement undoubtedly stem from the heterogeneity of the syndromes (Lhet $\vec{\theta}$ mitte and Signoret, 1972; Butters and Cermak 1975). But part is the result of the theoretical and practical difficulties of assessing premorbid memory in an irreversible amnesia. With transient global amnesia, the subject can serve as his or her own control, eliminating this major problem.

What evidence is available, from our patient and from the other detailed cases of transient global amnesia in the literature, suggests that the consolidation hypothesis cannot fully explain the extensive retrograde amnesia in these patients. Patten's (1971) patient failed to remember the death of a relative the year before. Shuttleworth and Wise (1973) report that their case 1 did not recall the events of his brother's death eight years previously, nor did he remember the Vietnam war. Likewise, our subject failed to recall or recognise information from 13 or more years before her illness-for example, the Kennedy assassination. From her excellent performance after the episode, we can infer that nothing was wrong with the strength of these memories per se. While her anterograde amnesia could still reflect a consolidation block, such temporally extensive retrograde

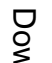


deficits in transient global amnesia seem to require some type of retrieval impairment for explanation. This supports the possibility that an analogous but less readily discoverable retrieval impairment underlies the retrograde amnesia of some of the classic amnestic states as well.

We thank Dr Guy McKhann, for permission to examine and report his patient, Dr Richard Johannes, the patient's resident, Dr Ernst Niedermeyer, for permission to cite the EEG report, and Rose Calini for superb secretarial assistance.

\section{References}

Bender, M. B. (1956). Syndrome of isolated episode of confusion with amnesia. Journal of the Hillside Hospital, 5, 212-215.

Butters, N., and Cermak, L. S. (1975). Some analyses of amnesic syndromes in brain-damaged patients. In The Hippocampus, vol. 2. Edited by $\mathrm{R}$. $\mathrm{H}$. Isaacson and K. H. Pribram. Plenum Press: New York.

Fisher, C. M., and Adams, R. D. (1964). Transient global amnesia. Acta Neurologica Scandinavica, 40, (suppl 9), 7-83.

Lhermitte, F., and Signoret, J. L. (1972). Analyse neuropsychologique et differenciation des syndromes amnesiques. Revue Neurologique, 126, 161-178.

Marslen-Wilson, W. D., and Teuber, H. L. (1975). Memory for remote events in anterograde amnesia: recognition of public figures from newsphotographs. Neuropsychologia, 13, 353-364.

Milner, B., Corkin, S., and Teuber, H. L. (1968). Further analysis of the hippocampal amnestic syndrome: 14 year follow up study of HM. Neuropsychologia, 6, 215-234.

Patten, B. M. (1971). Transient global amnesia syndrome. Journal of the American Medical Association, 217, 690-691.

Sanders, H. I., and Warrington, E. K. (1971). Memory for remo:e events in amnesic patients. Brain, 94, 661-668.

Sanders, H. I., and Warrington, E. K. (1975). Memory grade amnesia in organic amnesic patients. Cortex, 11, 397-400.

Seltzer, B., and Benson, D. F. (1974). The temporal pattern of retrograde amnesia in Korsakoff's disease. Neurology (Minneapolis), 24, 527-530.

Shuttleworth, E. C., and Morris, C. E. (1966). The transient global amnesia syndrome. Archives of Neurology (Chicago), 15, 515-520.

Shuttleworth, E. C., and Wise, G. R. (1973). Transient global amnesia due to arterial embolism. Archives of Neurology (Chicago), 29, 340-342.

Squire, L. R., and Slater, P. C. (1978). Anterograde and retrograde memory impairments in chronic amnesia. Neuropsychologica, 16, 313-322.

Victor, M., Adams, R. D., and Collins, G. H. (1971). The Wernicke-Korsakoff Syndrome. F. A. Davis: Philadelphia.

Warrington, E. K., and Weiskrantz, L.(1970). Amnesic syndrome: consolidation or retrieval? Nature, 228, 628-630. 